\title{
Green synthesis of biogenic silver particles, process parameter optimization and application as photocatalyst in dye degradation
}

\author{
Vartika Srivastava $^{1} \cdot$ Shipra Pandey $^{2} \cdot$ Aradhana Mishra $^{2} \cdot$ Abhay Kumar Choubey $^{1}$
}

Received: 30 April 2019 / Accepted: 22 November 2019 / Published online: 28 November 2019

(c) Springer Nature Switzerland AG 2019

\begin{abstract}
A stable dispersion of nano-structured silver particles (AgNPs) was synthesized using an aqueous extract of Citrus sinensis (orange) peel extract. Formation of AgNPs was confirmed using UV-visible spectroscopy. In the process, orange peel was used as both reducing agent and stabilizing agent. In the presence of extract, nanoparticles remained stable even after a time span of 20 days of their synthesis. Different physical parameters such as concentration of reducing agent, temperature, $\mathrm{pH}$ and time were being optimized for determination of optimal condition for synthesis of stable dispersion of nanoparticles. The AgNPs were further characterized using various techniques such as X-ray diffraction, dynamic light scattering, field emission scanning electron microscopy and energy-dispersive $X$-ray spectroscopy for getting information about their formation, composition, hydrodynamic diameter and size. The stability of the colloidal dispersion of nanoparticles over a wide range of temperatures and $\mathrm{pH}$ s was evaluated. The AgNPs were found to be stable over a pH range of 2-10 and temperatures ranging $25-75^{\circ} \mathrm{C}$. Later, these synthesized AgNPs were evaluated for their potentiality in antimicrobial activity. It was found that the nanoparticles showed significant bactericidal as well as fungicidal activity depending on the size of nanoparticles. In addition to this, AgNPs were evaluated for photocatalytic degradation of an azo dye, Congo red. Kinetic study of degradation has also been carried out and was found that the reaction followed pseudo-first-order kinetics.
\end{abstract}

Keywords Silver nanoparticles · Orange peel extract $\cdot \mathrm{pH} \cdot$ Temperature $\cdot$ Antimicrobial activity $\cdot$ Congo red · Photocatalyst

\section{Introduction}

Recently, nanoparticles have gained momentum due to their various beneficial applications in various fields. The unique feature of the nanoparticles is that their properties such as optical, magnetic and electronic vary from their bulk material [1]. The specific properties of nano materials have been attributed to the fact that these particles have characteristic size, shape, area and surface chemistry. Nanoparticles can be synthesized using a variety of methods such as laser ablation, photochemical reduction and sono-chemical method [2-5]. Though there are several processes available for synthesis of these particles, the processes using chemicals are not eco-friendly and relatively expensive. An alternative way needs to be searched which should be environmental-friendly and cheaper. The most efficient and cost-effective method for synthesis of metal nanoparticles is synthesis using natural resources like plant or fruit or fruit peel extract as stabilizing and reducing agent [6-8]. The recent literature revealed the enthusiasm of green route to synthesize AgNPs using banana peel extract [9], Azadirachta indica leaf [10], Garcinia

$\triangle$ Abhay Kumar Choubey, achoubey@rgipt.ac.in | ${ }^{1}$ Rajiv Gandhi Institute of Petroleum Technology, Bahadurpur, Mukhetia More, Post: Harbanshganj, Jais, Amethi, Uttar Pradesh 229304, India. ${ }^{2}$ CSIR National Botanical Research Institute, Rana Pratap Marg, Lucknow, Uttar Pradesh 226001, India. 
mangostana leaf [11], Terminalia arjuna leaf [12], Murraya koenigii leaf [13], Punicia granatum peel [14] and Cinnamomum zeylanicum leaf [15]. Therefore, this green process can be used for production of nanoparticles at large scale also. Biogenic methods of synthesis of nanoparticles have several advantages over physiochemical method. Besides being environmental-friendly and non-toxic in nature, this method leads to production of nanoparticles having well-defined morphology and size [1]. In the proposed work, Citrus sinensis has been employed for the synthesis of nanoparticles. Citrus sinensis (orange) belonging to a family Rutaceae are mainly found in dry and arid regions of tropical and subtropical areas.

Metal nanoparticles have got vital role in various areas such as pharmaceutical, biotechnological and industrial. In particular, silver nanoparticles possess antibacterial, antifungal and larvicidal properties [16-18]. In fact, silver has the lowest toxicity to animal cells and was found to be most effective against bacterial action. Besides their antimicrobial property, AgNPs also exhibit photocatalytic properties in the field of dye detoxification and its removal [19-21]. Dyes are used in different industries and are directly discharged into the water bodies without any treatment. These dyes which are non-biodegradable and potentially hazardous can cause serious damage to ecology $[22,23]$. Various other methods are also being practiced for treatment of waste water such as UV light degradation, redox treatment, carbon sorption and flocculation; however, these techniques are not that effective and, therefore, need better approach [24-27].

The objective of this work is to yield relatively stable dispersion of AgNPs in a simple and cheap manner by reducing the silver salt solution using orange peel extract. Peel extract was used as both reducing agent and stabilizing agent. Optimal condition to obtain stable dispersion of AgNPs was obtained by evaluating different parameters such as $\mathrm{pH}$, temperature and concentration of reducing agent. The synthesized nanoparticles were then evaluated for its antimicrobial property, and finally, these AgNPs were also used as photocatalyst for the removal of an azo dye, i.e. Congo red, present in waste water and the kinetic study of degradation has also been reported.

\section{Experimental}

\subsection{Materials}

Silver nitrate $\left(\mathrm{AgNO}_{3}\right.$, Extra Pure, 99\%) and sodium borohydride of Molychem were being used for different purposes. The $\mathrm{pH}$ of each solution was adjusted to 8 using $0.1 \mathrm{M}$ sodium hydroxide (Sigma Aldrich) and $0.1 \mathrm{M}$ hydrochloric acid (Fischer Scientific) solution. Citrus sinensis peels were collected from the local market. A total of two bacterial strains, namely Pseudomonas aeruginosa (P.aeruginosa) and Pseudomonas syringae ( $P$. syringae), and a fungal strain, Alternaria brassicicola (A. brassicicola), were used in the study. The bacterial and fungal strains were obtained from CSIR-National Botanical Research Institute, Lucknow, India. For preparation of solution, double distilled water was used.

\subsection{Synthesis of AgNPs}

Extracted component of orange peel was used as stabilizing and reducing agent for the synthesis of AgNPs. $10 \mathrm{~g}$ of orange peel was dried in sunlight for 4-5 days. It was taken in a round-bottomed flask where $200 \mathrm{~mL}$ metha$\mathrm{nol} /$ water solution was then added to it in the ratio of 4:1 $(\mathrm{v} / \mathrm{v})$. The resulting solution was placed on a heating mantle with stirrer and was refluxed for 4-5 h. The solvent was removed from the solution using rotary evaporator (Heidolph Laborota 4001 Rotary Evaporator). The extract was dried and further converted into powdered form. The powdered form of the extract was used for further experiments. A required amount of this powdered extract was mixed with known amount of double distilled water to achieve the desired concentration and the final volume of $15 \mathrm{~mL}$. The preparation of AgNPs was carried out by adding $25 \mathrm{~mL}$ of $600 \mathrm{ppm}$ silver nitrate solution to $15 \mathrm{~mL}$ of prepared extract solution while stirring ( $1000 \mathrm{rpm})$. Four solutions of AgNPs were prepared, and in each of the solutions, the concentration of silver nitrate was kept $600 \mathrm{ppm}$ while the concentration of peel extracts was kept 0,300 , $1500,3000 \mathrm{ppm}$, respectively. In this method, $\mathrm{K}_{\mathrm{Ext} / \mathrm{Ag}}$ depicts the ratio of extracted component to silver ion concentration. Table 1 presents the value of this ratio for all the samples. Once the formation of nanoparticles was completed, nanoparticles were washed by ultracentrifugation at $14,000 \mathrm{rpm}$ for $20 \mathrm{~min}$. The liquid was removed, and the powder obtained at the bottom of the centrifuge tubes was suspended in deionized water. The suspension was again centrifuged at 14,000 rpm for $20 \mathrm{~min}$, and the process was repeated thrice. Finally, the powder obtained was suspended in water and sonicated using Q Sonica Sonicator at room temperature. Variation in the $\mathrm{pH}$ of extract solution has an effect on synthesis reaction, and

Table 1 Composition of sample solution

\begin{tabular}{llcll}
\hline Sample & $K_{\text {Ext/Ag }}$ & {$[$ Extract $](\mathrm{ppm})$} & {$\left[\mathrm{Ag}^{+}\right](\mathrm{ppm})$} & {$\left[\mathrm{NaBH}_{4}\right](\mathrm{ppm})$} \\
\hline 1 & 0.0 & 0 & 600 & 300 \\
2 & 0.5 & 300 & 600 & 0.0 \\
3 & 2.5 & 1500 & 600 & 0.0 \\
4 & 5.0 & 3000 & 600 & 0.0 \\
\hline
\end{tabular}


to avoid this, $\mathrm{pH}$ of the peel extract was set to 7 in all the cases before mixing.

\subsection{Characterization of AgNPs}

At the initial stage, the synthesis of AgNPs was monitored using LAB India UV-Vis 3200 spectrophotometer in a wavelength range of $300-700 \mathrm{~nm}$. A glass cuvette having optical path of $1 \mathrm{~cm}$ was used. The stability of colloidal AgNPs was studied by taking the UV-Vis absorption spectra of all samples after 30 min of synthesis and was compared with spectra taken after 7 days and then after 20 days. The UV-Vis absorption spectra for different samples were taken at room temperature. PANalytical X'pert Pro MPD diffractometer was used to perform powder XRD to obtain the diffraction pattern from the sample. The AgNPs were further characterized by DLS study using a Nano Brook 90 plus PALS at $25^{\circ} \mathrm{C}$. The hydrodynamic diameter (Z-average), PDI and width distribution of particles were also determined through DLS study. Morphology and size of the nanoparticles were determined using FESEM. FESEM images of the nanoparticles were taken by using ZEISS microscope (accelerating voltage ranged from 5 to $20 \mathrm{kV}$ ). FESEM samples were prepared by placing 2 $\mu \mathrm{L}$ of AgNPs on thin aluminium foil. The chemical composition was verified using elemental analysis on a ZEISS electron microscope equipped with an EDX analyser. To prevent samples from charging, a thin gold coating was sputtered onto the samples prior to the analysis. Coating the sample with a layer of metal resists charging, prevents thermal damage and improves the secondary electron signals, which is required for topographic examination of the sample.

\section{Stability of AgNPs at different pHs and temperatures}

The colloidal stability of synthesized AgNPs was screened at different $\mathrm{pHs}$ and temperatures. The hydrodynamic diameter and PDI of the nanoparticles were measured over a $\mathrm{pH}$ range of $2-10$ and temperature range of $25-75^{\circ} \mathrm{C}$ using NanoBrook 90 plus PALS. 0.1 M NaOH solution and $0.1 \mathrm{M} \mathrm{HCl}$ were used to adjust the desired $\mathrm{pH}$ environment.

\section{Antimicrobial assay of AgNPs}

\subsection{Antibacterial activity assessment}

Antibacterial potential of biogenic AgNPs of different $\mathrm{K}_{\mathrm{Ext} / \mathrm{Ag}}$ ratios was tested against $P$ seudomonas aeruginosa and Pseudomonas syringae (Gram-negative bacteria) by disc diffusion method [28]. To study the effect of AgNPs on pathogens, $100 \mu \mathrm{l}$ of cultures, which were allowed to grow overnight, was spread on nutrient agar plates in a uniform manner. Pre-sterilized cotton of $1 \mathrm{~cm}^{2}$ was placed on the centre of the plates, and $50 \mu \mathrm{L}$ of desired nanoparticles was added to it and was dried in air. The plates were incubated at $27^{\circ} \mathrm{C}$ for $24 \mathrm{~h}$. After $24 \mathrm{~h}$, zone of inhibition was measured. Peel extract (3000 ppm) was used as control in the process.

\subsection{Antifungal activity evaluation}

Antifungal assay of the synthesized nanoparticles against Alternaria brassicicola was conducted to evaluate the effect of AgNPs on the mycelial growth of the fungi. Three plates of autoclaved potato dextrose agar (PDA) were prepared in which nanoparticles synthesized using different $K_{\mathrm{Ext} / \mathrm{Ag}}$ ratios were added to each of these plates. The other plate was kept as control containing only Milli-Q Water (without AgNPs). A disc of mycelia was withdrawn from the fungal culture and was placed at the centre of the plate containing silver nanoparticles assimilated in PDA Medium. The plates were then incubated at $25^{\circ} \mathrm{C}$ temperature for 7 days. The efficiency of the synthesized nanoparticles was evaluated by measuring the diameter of the fungal colony growth.

\section{Photocatalysis}

The photocatalytic activity of the AgNPs was studied by employing an aqueous solution of an azo dye, i.e. Congo red $\left(20 \mathrm{mg} \mathrm{L}^{-1}\right)$. Thereafter, the photocatalytic reaction was conducted outdoor under the sunlight as main energy source. The experiment was set up by suspending $5 \mathrm{~mL}$ of AgNPs solution in $50 \mathrm{~mL}$ of dye solution. The mixture was kept in dark under continuous stirring for 30 min to bring the AgNPs to constant equilibrium in the mixture. The mixture was then kept under sunlight for 4-5 h. Degradation of congo red aqueous solution was analysed using UV-Vis spectroscopy by collecting the samples at regular time interval. The kinetics of the reaction has also been studied.

\section{Results and discussion}

\subsection{Visual change}

The preliminary analysis, which indicates the synthesis of nanoparticles, is the visible change in the colour on addition of peel extract to the silver nitrate solution. On adding different concentrations of peel extract to silver nitrate, a significant change in colour was observed. The colour of 
the solution turned from colourless to orange when the extract ratio was 0.5 , and on increasing the extract ratio to 2.5 , brown colour was observed, which turned to dark brown on further increasing the extract ratio to 5.0. The reason for the change in colour is excitation in the surface plasmon resonance (SPR). The SPR is a distinctive optical property, which is exhibited when all the electrons present in conduction band vibrate in resonance, which, in turn, is responsible for the absorption ranging between 380 and $500 \mathrm{~nm}$ in UV-Vis spectra for the synthesized silver nanoparticles. Thus, the colour change confirmed the synthesis of silver nanoparticle, which was further confirmed using UV-Vis spectrometer.

\subsection{UV-Vis results}

UV-Vis absorption spectra of the prepared samples at different concentrations of peel extract are presented in Figs. 1 and 2. Figure 1 shows the UV-Vis spectra of nanoparticles at various extracted concentrations immediately after their synthesis. The concentration of peel extract influenced the intensity of extinction peak. With the increase in concentration of peel extract, the probability of aggregation of nanoparticles decreased and the rate of nucleation increased, which results in the synthesis of large number of nanoparticles [29, 30]. The functional group of the stabilizer reacted with the nanoparticles and did not allow the collision of these nanoparticles; therefore, the aggregation of nanoparticles did not occur. The appearance of peak in the range of $400-420 \mathrm{~nm}$ confirms the synthesis of AgNPs [31].

UV-Vis absorption spectrum of the synthesized nanoparticles using sodium borohydride as reducing agent and without adding peel extract (stabilizing agent) is depicted in Fig. 2a. The UV-Vis spectrum taken immediately after synthesizing AgNPs showed peak at $390 \mathrm{~nm}$,

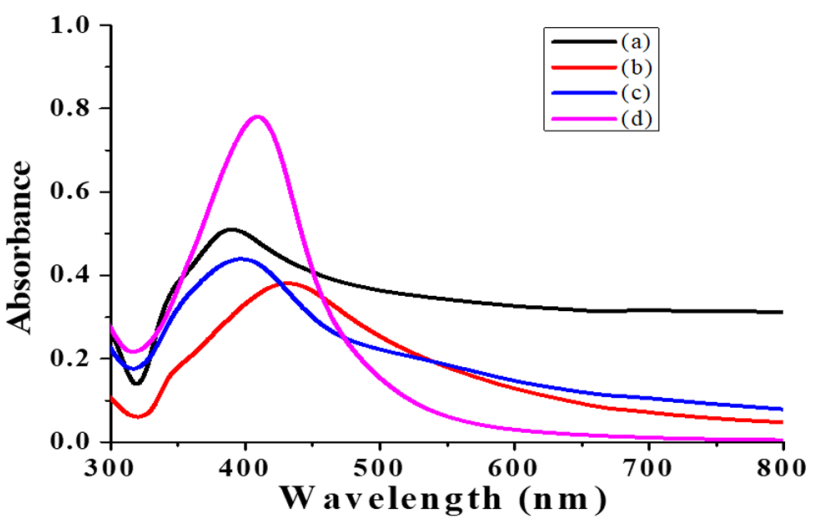

Fig. 1 UV-Vis absorption spectra of synthesized AgNPs after 30 min in solution a without extract, b $K_{\mathrm{Ext} / \mathrm{Ag}}=0.5, \mathbf{c} K_{\mathrm{Ext} / \mathrm{Ag}}=2.5$ and $\mathbf{d}$ $K_{\text {ExtAg }}=5.0$ which indicated the formation of spherical AgNPs, but the spectrum taken after 1 day did not show any peak. The peak at $390 \mathrm{~nm}$ disappeared which illustrated the instability of synthesized nanoparticles while spectrum of the nanoparticles obtained in the presence of peel showed no changes even after a week time. The UV-Vis absorption spectrum for nanoparticles having $K_{\mathrm{Ext} / \mathrm{Ag}}=0.5$ and 2.5 was stable even after a week, but the stability of nanoparticles obtained from $K_{\mathrm{Ext} / \mathrm{Ag}}=5.0$ was even higher (Fig. $2 \mathrm{~b}-\mathrm{d}$ ). There are two factors, which determine the stability of nanoparticles. These are (a) changes in the maximum absorption wavelength (b) sharpness of the peak. AgNPs having lowest change in the absorption and also sharpest peak have the highest stability [32]. Based on these results, the solution of nanoparticles with $K_{\mathrm{Ext} / \mathrm{Ag}}=5.0$ has the highest stability. This shows that peel extract acts as a stabilizer and the increase in its concentration increased the stability of nanoparticles. Even slight change in the shape, size and distribution of the solution has an influence on the UV-Vis extinction characteristics such as shifting of the peak, intensity and full width half maxima [30]. The results obtained are well in agreement with those reported in Santiago et al.

\subsection{XRD analysis}

Figure 3 represents the XRD pattern of the nanoparticles synthesized at $45^{\circ} \mathrm{C}$ and $\mathrm{pH} 10$. The peaks at $35.6,42.79$, $48.16,57.10$ and 64.33 are assigned to diffraction from [111], [220], [200], [222] and [220] planes of face-centred cubic silver nanoparticles. The peaks have been matched with the standard data file (The JCPDS Card no. 04-0784).

\subsection{DLS results}

The effect of different amounts of peel extract on Z-average of AgNPs is demonstrated in Table 2. An increase in the extract concentration resulted in decrease in the size of AgNPs. Figure 4 depicts the size of nanoparticles obtained from different $\mathrm{K}_{\mathrm{Ext} / \mathrm{Ag}}$ ratios. These trends can be explained by the fact that an increase in concentration of extract controls the growth of nanoparticles as a result of which the size of nanoparticles decreases. The sample having $K_{\text {Ext } / A g}=5.0$ exhibited the lowest PDI value. All the four samples having PDI value lower than $\sim 0.3$ indicate narrow particle size distribution [30].

\subsection{FESEM results}

FESEM images of synthesized AgNPs are presented in Fig. 5. The micrographs were taken at $1 \mu \mathrm{m}$ (low resolution) and $100 \mathrm{~nm}$ (high resolution). FESEM images show that synthesized nanoparticles are uniformly spherical in 

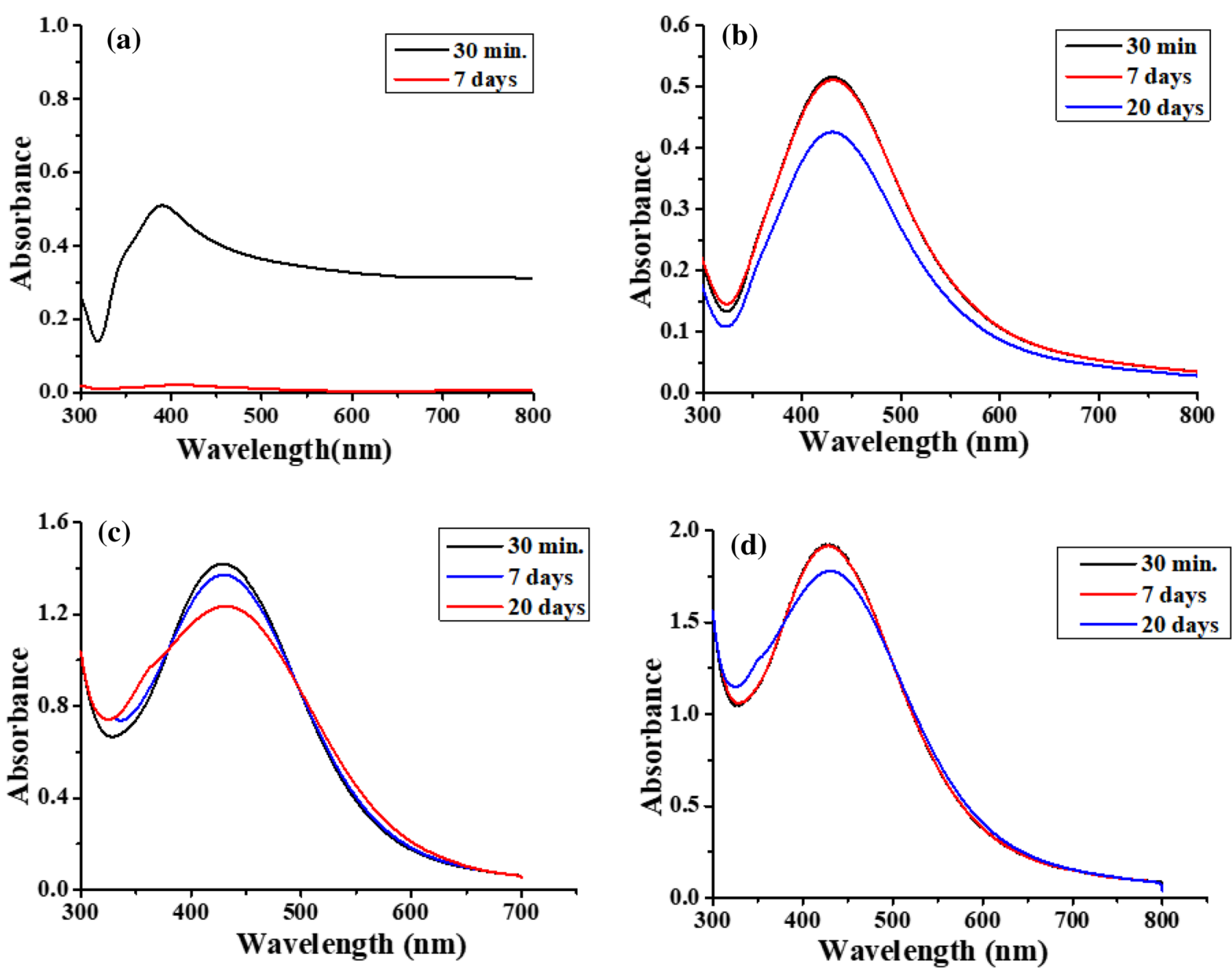

Fig. 2 UV-Vis absorption spectra of synthesized AgNPs over a period of time a [Extract] $=0$ ppm, $\mathrm{NaBH}_{4}$ was used as reducing agent, $\mathbf{b}$ $K_{\mathrm{Ext} / \mathrm{Ag}}=0.5, \mathbf{c} K_{\mathrm{Ext} / \mathrm{Ag}}=2.5$ and $\mathbf{d} K_{\mathrm{Ext} / \mathrm{Ag}}=5.0$

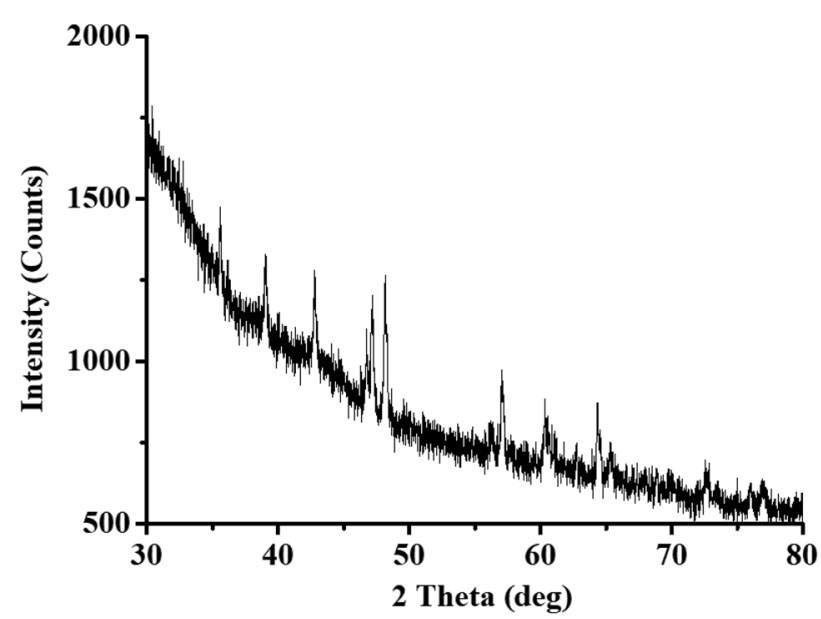

Fig. 3 XRD pattern of AgNPs synthesized using $K_{\text {Ext } / \mathrm{Ag}}$ ratio $=5.0$
Table 2 Effect of different concentrations of peel extract on Z-average and zeta potential of AgNPs

\begin{tabular}{llll}
\hline$K_{\text {Ext/Ag }}$ & $Z$-average $(\mathrm{nm})$ & Zeta potential $(\mathrm{mV})$ & PDI \\
\hline 0 & Precipitated & Precipitated & 1.00 \\
0.5 & 149 & -25.79 & 0.326 \\
2.5 & 58.5 & -28.06 & 0.320 \\
5.0 & 46.6 & -26.97 & 0.259 \\
\hline
\end{tabular}

shape. The AgNPs, which were not stabilized by extract solution, were easily agglomerated and linked created large particles. The size of nanoparticles reduced with increasing $\mathrm{K}_{\mathrm{Ext} / \mathrm{Ag}}$ ratio. 
Fig. 4 Hydrodynamic diameter of silver nanoparticles a $K_{\text {Ext } / \mathrm{Ag}}=0.5, \mathbf{b} K_{\mathrm{Ext} / \mathrm{Ag}}=2.5$ and $\mathbf{c}$ $K_{\mathrm{Ext} / \mathrm{Ag}}=5.0$
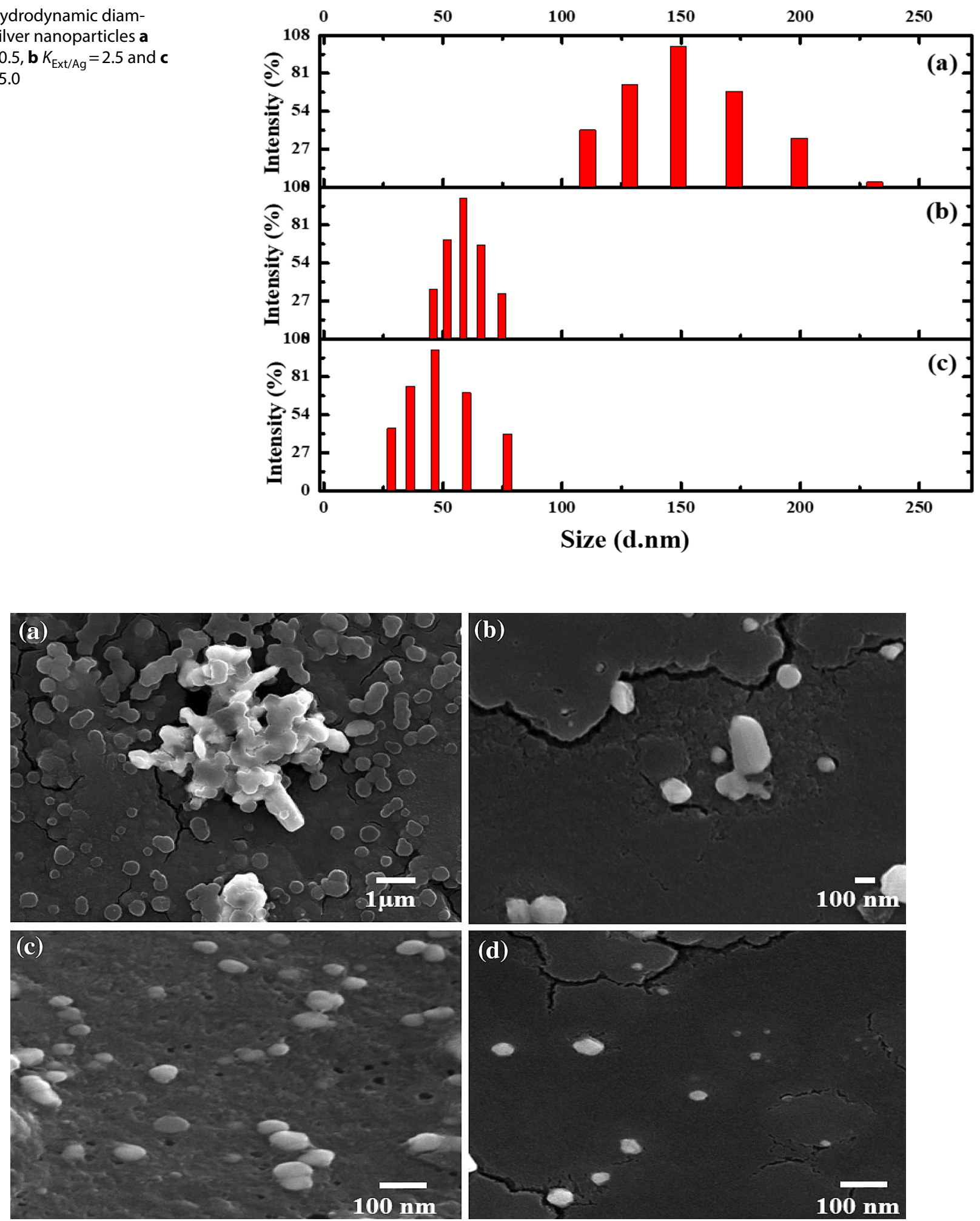

Fig. 5 SEM images of synthesized AgNPs a without extract, $\mathbf{b} K_{\mathrm{Ext} / \mathrm{Ag}}=0.5, \mathbf{c} K_{\mathrm{Ext} / \mathrm{Ag}}=2.5$ and $\mathbf{d} K_{\mathrm{Ext} / \mathrm{Ag}}=5.0$ 


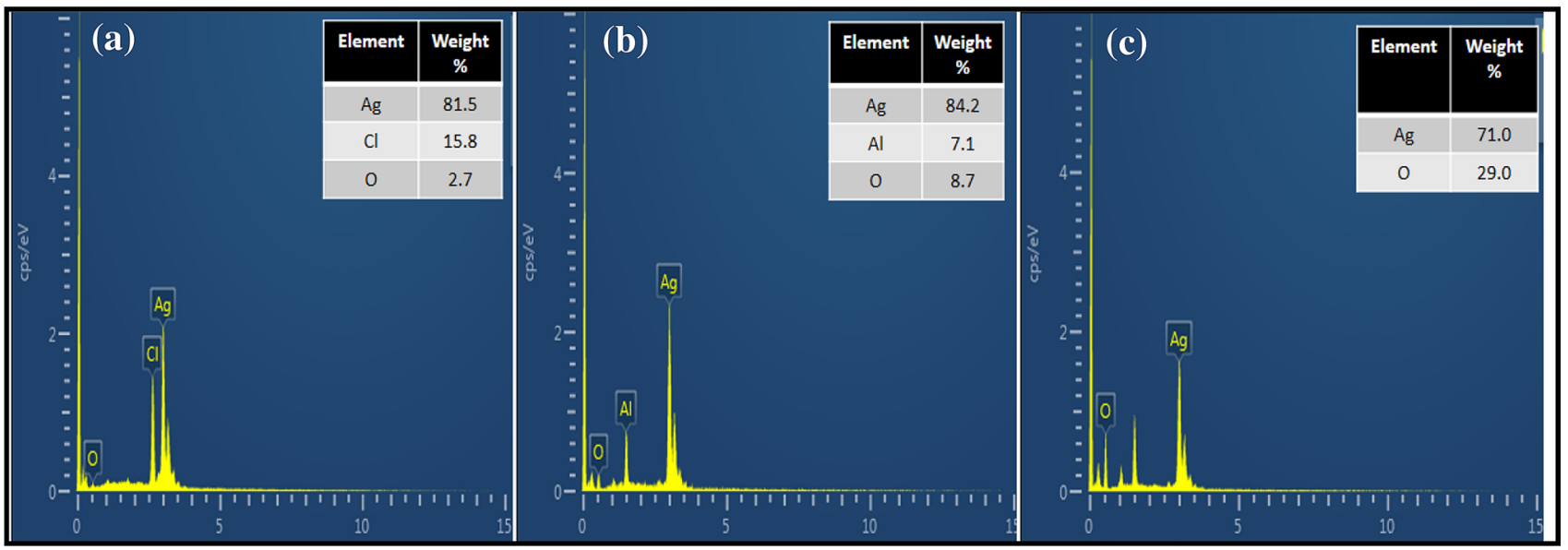

Fig. 6 EDX spectrum of AgNPs a $K_{\mathrm{Ext} / \mathrm{Ag}}=0.5, \mathbf{b} K_{\mathrm{Ext} / \mathrm{Ag}}=2.5$ and $\mathbf{c} K_{\mathrm{Ext} / \mathrm{Ag}}=5.0$

\subsection{EDX analysis}

EDX spectra recorded from the silver nanoparticles are shown in Fig. 6. The EDX spectra show the presence of $\mathrm{Ag}$ and $\mathrm{O}$. The strong signal of $\mathrm{Ag}$ confirms the synthesis of AgNPs while $O$ may have originated from the biomolecules, which are capped on to the silver nanoparticles. A typical optical absorption peak at $3 \mathrm{keV}$ is generally shown by silver nanoparticles due to SPR [33, 34]. The variation in the intensity of $O$ peak with the size of capping molecule depicts that AgNPs are in metallic form with no formation of $\mathrm{Ag}_{2} \mathrm{O}$ in them and free from any other impurities. Other weaker signals from $\mathrm{Cl}, \mathrm{P}, \mathrm{Na}$ \& $\mathrm{Ca}$ atoms have also been observed due to the presence of impurities in plant extract. Al was also observed as the sample was drop casted on Al foil.
Fig. 7 Hydrodynamic diameter and polydispersity index with changing $\mathbf{a} \mathrm{pH}$ and $\mathbf{b}$ temperature for AgNPs with extract concentration $=1500 \mathrm{ppm}$
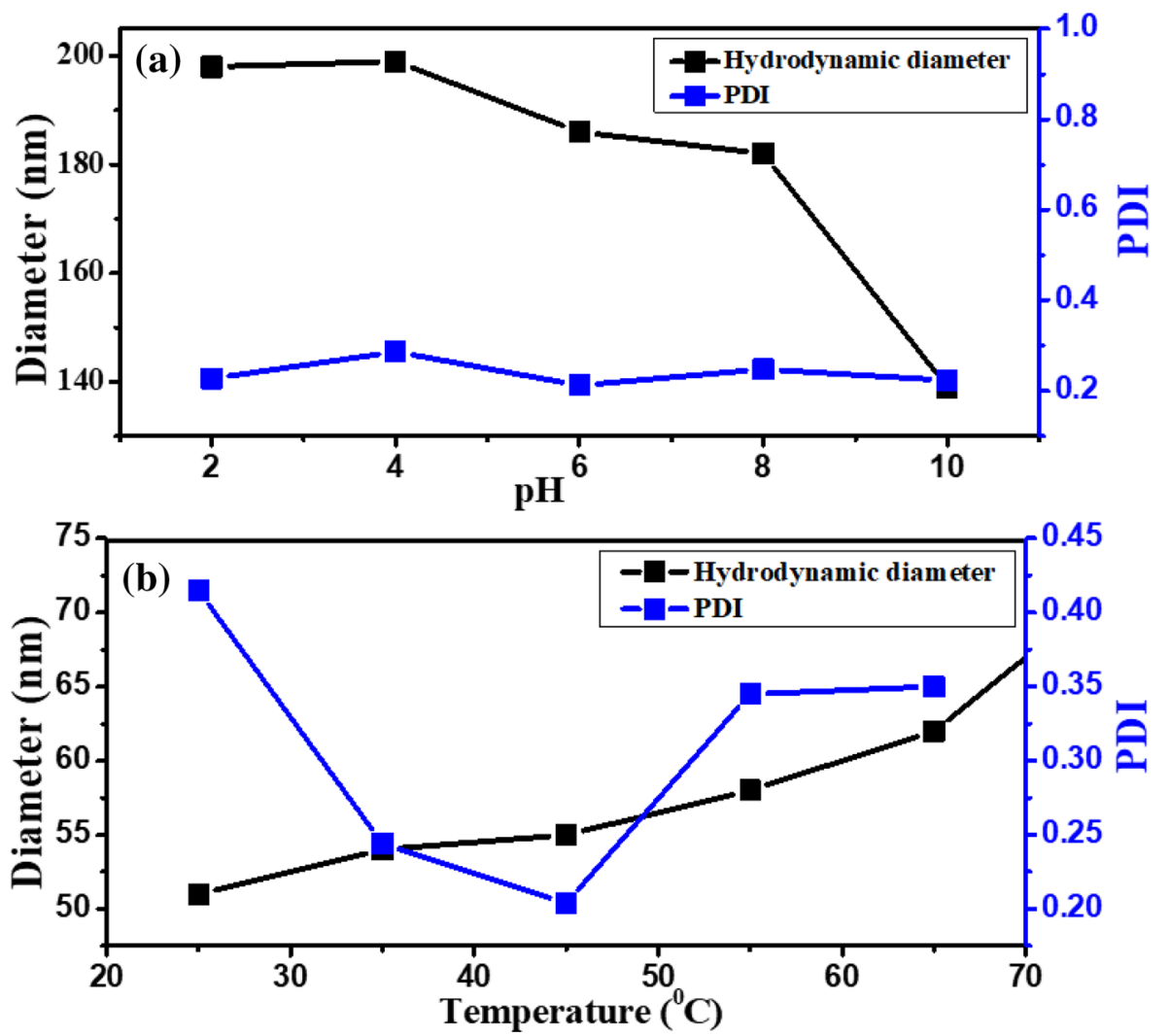

SN Applied Sciences 


\subsection{Effect of pH on the stability of AgNPs}

The colloidal stability of synthesized nanoparticles with $K_{\mathrm{Ext} / \mathrm{Ag}}=0.5$ was evaluated using particle size analyser in a pH range of 2-10. The size and the PDI of the nanoparticles remained almost the same over the wide range of pH (Fig. 7a). There wasn't a significant variation in the size of nanoparticle in the $\mathrm{pH}$ range of $2-8$. The size of the particles in the $\mathrm{pH}$ range 2-8 varied from 198 to $186 \mathrm{~nm}$. In contrast, a further increase in $\mathrm{pH}$ resulted in considerable decrease in the size of the nanoparticle $(139 \mathrm{~nm})$. The PDI of the nanoparticles remained almost the same in the $\mathrm{pH}$ range of $2-10$. The lower value of PDI (0.212-0.286) indicates the homogeneity of nanoparticles which means particles have narrow particle size distribution.

\subsection{Stability of nanoparticles at different temperatures}

The stability of nanoparticles was studied over a temperature range $25-75^{\circ} \mathrm{C}$. The particle size and PDI of synthesized nanoparticles using $K_{\mathrm{Ext} / \mathrm{Ag}}=0.5$ with varying temperature are shown in Fig. $7 \mathrm{~b}$. The size of the nanoparticles increased from 51 to $72 \mathrm{~nm}$ on increasing the temperature from 25 to $75^{\circ} \mathrm{C}$. The PDI of synthesized nanoparticles decreased till $45^{\circ} \mathrm{C}$ (from 0.415 to 0.204 ), then increased at $55^{\circ} \mathrm{C}$ and then further decreased. The PDI presents the homogeneity of the size distribution in a dispersion of colloidal AgNPs. A lower PDI indicates the presence of more homogeneous particles. Therefore, the most optimum temperature for the stability of nanoparticles was found to be $45^{\circ} \mathrm{C}$ at which the particles were smaller in size and homogenous in nature.
Table 3 Zone of inhibition (Mean \pm SD) exhibited by AgNPs against Gram-negative bacteria $P$. syringae and $P$. aeruginosa

\begin{tabular}{llc}
\hline$K_{\text {Ext } / \mathrm{Ag}}$ & \multicolumn{2}{l}{ Zone of inhibition $(\mathrm{mm})$} \\
\cline { 2 - 3 } & P. syringae & P. aeruginosa \\
\hline 0.5 & $20.833 \pm 0.8498$ & $0.0 \pm 0.0$ \\
2.5 & $24.833 \pm 0.6236$ & $12.166 \pm 0.2357$ \\
5.0 & $26.33 \pm 0.6236$ & $14.33 \pm 0.2357$ \\
\hline
\end{tabular}

\subsection{Antibacterial assay result}

The antibacterial activity of AgNPs was determined by zone inhibition method with Gram-negative bacteria's $P$. syringae and $P$. aeruginosa. AgNPs synthesized using orange peel extract showed inhibitory activity against both of them. AgNPs synthesized using three different $K_{\text {Ext/Ag }}$ ratios were used for the analysis of antibacterial activity. Figure $8 a(1), b(1)$ represents the antibacterial activity of peel extract. Orange peel extract did not show any zone of inhibition confirming itself having no antibacterial property [35]. The diameter of inhibition zone against $P$. syringae and $P$. aeruginosa is given in Table 3 . The inhibition zone varies from one bacterial species to another due to variation in the composition of their cell wall $[36,37]$.

The highest $K_{\text {Ext/Ag }}$ ratio of 5.0 exhibited maximum antibacterial activity as compared to other counterparts. As observed in Fig. 8, the diameter of zone of inhibition increased with the increase in $K_{\mathrm{Ext} / \mathrm{Ag}}$ ratio, which reflects that synthesized AgNPs using higher concentration of extract exhibited higher bactericidal properties as compared to others.

The increase in the antibacterial activity is because of the fact that with increase in the concentration of peel extract, small-sized nanoparticles were obtained (Table 2) due to which larger surface area became available for the
Fig. 8 Antibacterial activity of biogenic AgNPs against a $P$. syringae and $\mathbf{b} P$. aeruginosa (1) peel extract (2) $K_{\mathrm{Ext} / \mathrm{Ag}}=0.5$ (3) $K_{\text {Ext } / \mathrm{Ag}}=2.5$ and $(4) K_{\mathrm{Ext} / \mathrm{Ag}}=5.0$ (in both the cases)
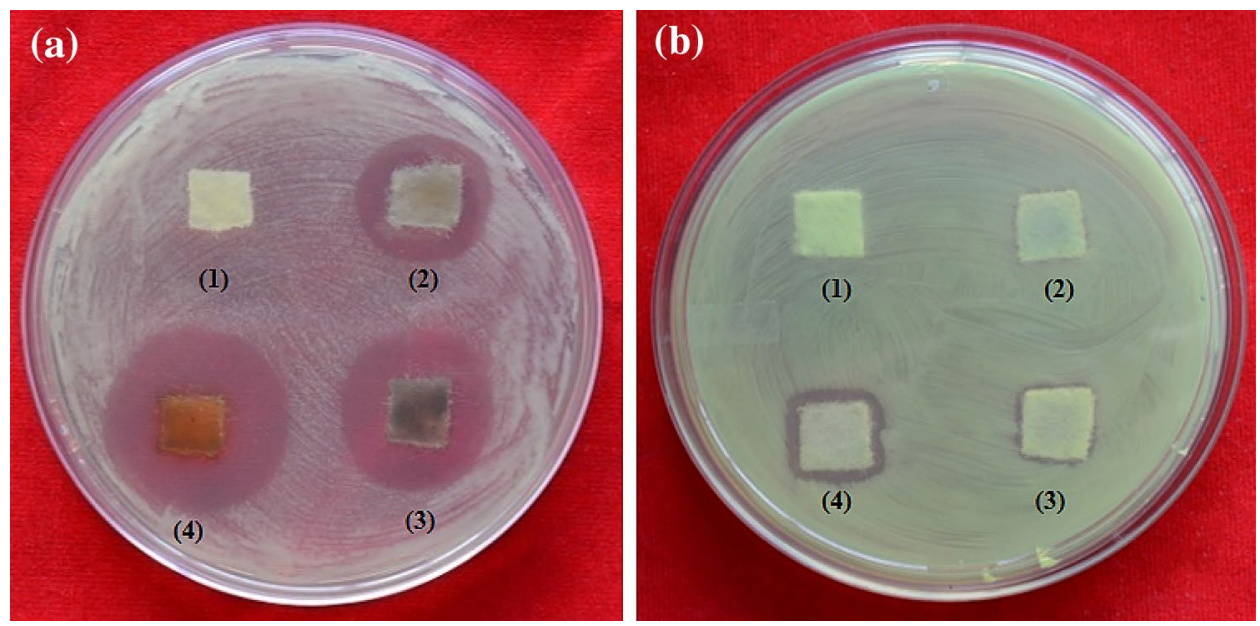
interaction, and hence, bactericidal activities increased as compared to large-sized particles and killed the microorganism [35, 38].

When nanoparticles interacted with the bacterial membrane, certain changes occurred on bacterial surface. The changes produced on the surface of bacterial membrane lead to increase in its permeability, which ultimately affected the transport through plasma membrane. The disturbance in the transportation through plasma membrane consequently caused cell death $[39,40]$. The silver nanoparticles, which penetrated the bacterial surface, interacted with compounds containing sulphur and phosphorous [41] and disturbed the regular cycle leading to ultimate demise of the cell. In case of Psedomonas syringae, an increase in the $K_{\text {Extact/Ag }}$ ratio resulted in increase in the killing rate of bacteria. Psedomonas aeruginosa also exhibited the same trend, but the zone of inhibition exhibited by it was comparatively smaller as compared to Pseudomonas syringae (as shown in Table 3). Similar kind of results has been reported when AgNPs were used to kill E. coli and S. aureus [42].

\subsection{Antifungal assay result}

The effect of AgNPs on the mycelial growth of fungi, Alternaria brassicicola, was observed after 7 days. The diameter of the mycelial growth decreased with increase in the $K_{\mathrm{Ext} / \mathrm{Ag}}$ ratio (Table 4). Although the growth of fungi

Table 4 Fungal growth (colony diameter, $\mathrm{mm}$ ) in the presence of AgNPs synthesized using variable $K_{\text {Ext/Ag }}$

\begin{tabular}{ll}
\hline$K_{\text {Ext/Ag }}$ & $\begin{array}{l}\text { Diameter of fungal }(A . \\
\text { brassicicola) growth } \\
(\mathrm{mm})\end{array}$ \\
\hline 0.5 & $55.5 \pm 1.0$ \\
2.5 & $30.0 \pm 1.0$ \\
5.0 & $27.7 \pm 0.7$ \\
\hline
\end{tabular}

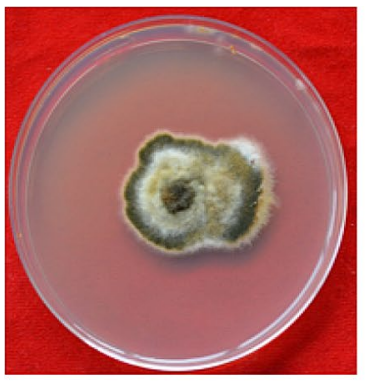

(a)

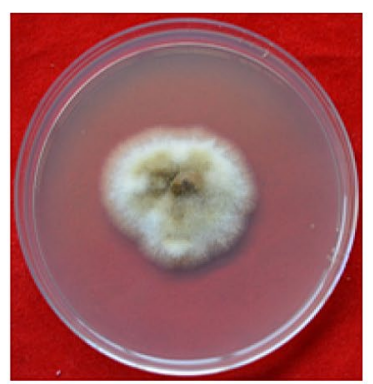

(b)

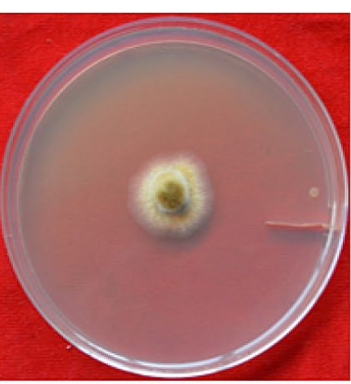

(c)

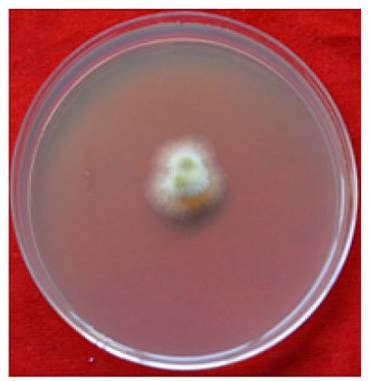

(d)

Fig. 9 Images showing mycelial growth of $A$. brassicicola on PDA medium containing nanoparticles synthesized using a $K_{\mathrm{Ext} / \mathrm{Ag}}=0$ (peel extract), $\mathbf{b} K_{\mathrm{Ext} / \mathrm{Ag}}=0.5, \mathbf{c} K_{\mathrm{Ext} / \mathrm{Ag}}=2.5$ and $\mathbf{d} K_{\mathrm{Ext} / \mathrm{Ag}}=5.0$ 


\section{Mechanism of silver nanoparticles synthesis using orange peel}

The orange peel extract is composed of various polyphenolic compounds such as tannins flavonoids, alkaloids, saponins, quinines and steroids. These chemical compounds are responsible for the instantaneous reduction of the silver ions in the reaction mixture [44]. Extract was prepared using methanol/water solution because of the fact that although the phytochemicals present in the plant extract are soluble in water, the maximum extraction of these compounds occurs in the presence of methanol. Several workers have reported the potential of solvents for phytochemical extraction $[45,46]$. Among various active constituents present in the peel extract, one of them is ellagic acid, which is an antioxidant and has the ability to scavenge the free radicals. Ellagic acid possess hydroxyl and carboxyl groups, which have strong tendency to bind the heavy metal ions [47]. Polyphenols and phenolic derivatives have strong nature to form chelated compound [48] and, therefore, inactivate the metal ion [49]. The inactivation of metal ions and formation of chelated compounds plays an important role in the formation of metal nanoparticles [50]. When silver nitrate comes in contact with the peel extract, the hydroxyl group present in the plant extract gets esterified as a result of elimination of reactive unpaired electrons in oxygen radicals. The eliminated electrons are transferred to hydroxyl group. This causes the reduction of $\mathrm{Ag}^{+}$ions to atomic Ag. The esterification of the hydroxyl and carbonyl present in ellagic acid makes easier for the hydrogen atom to leave ortho-phenolic hydroxyl group; thus, the phenolic group is oxidized. The oxidation of phenolic group results in the formation of quinone or quinoid (Fig. 11a). The reduction of $\mathrm{Ag}^{+}$ions to $\mathrm{Ag}$ is facilitated by the higher total phenolic content of the orange peel extract. The electron-donating tendency of the phenolic group makes it suitable for reducing silver ion to nano-size silver atoms. The quinoid compounds, which are synthesized by the oxidation of phenolic group, get adsorbed on the surface of synthesized nanoparticles and hence get stabilized (Fig. 11b). By this way, the orange peel extract acts as both reducing agent and stabilizing agent.

\section{Photocatalysis}

Firstly, the catalytic degradation of Congo red dye in the presence of AgNPs was observed by visual change in the colour. The intensity of the colour of dye gradually decreased with time from red to light yellow in the presence of AgNPs under sunlight. Congo red is a secondary diazo dye and is a carcinogenic metabolite, which is used in many industries. It is a coloured dye and has high amount of dissolved solid along with high chemical oxygen demand [51]. The degradation of the dye solution using AgNPs in the presence of sunlight was confirmed using UV-Vis spectrophotometer (Fig. 12b). Figure 12a exhibits the change in intensity of peak of the dye solution in the absence of sunlight, which reveals that a small shift in the intensity occurred in a time span of $2 \mathrm{~h}$ but at extremely slow pace. The characteristic peak for Congo red was obtained at $507 \mathrm{~nm}$ and $355 \mathrm{~nm}$, which corresponds to $\pi-\pi *$ transitions of azo group $(-N=N-)$ and naphthalene rings of the dye, respectively [52]. After the addition of AgNPs, the solution was stirred in the absence of light for $30 \mathrm{~min}$ in order to attain the adsorption-desorption equilibria. The removal of dye at the initial stage reflects the capability of dye molecules to get adsorbed on the surface of nanoparticles [53]. The dye molecules were adsorbed on to the active sites of the surface of nanoparticle through the oxygen atoms of the sulphonate group present in Congo red dye. After sometime, the active sites of AgNPs were saturated with the dye molecules being adsorbed on its surface. Consequently, there wasn't any space left for further adsorption and the process of adsorption was then followed by photodegradation. The gradual decrease in the peak intensity confirmed the degradation of dye. There was complete change in the colour of the dye from bright red to light yellow colour at the end of $4 \mathrm{~h}$.

On exposing the Congo red solution to the solar radiation, the peak observed at $507 \mathrm{~nm}$ suppressed significantly, which depicts the mineralization of azo bonds by the attack of hydroxyl radicals. On the other hand, the peak centred at $355 \mathrm{~nm}$, which was attributed to naphthalene ring, exhibited a lesser suppression. Thus, it can be concluded that azo bonds are more susceptible to degradation by hydroxyl radicals as compared to the aromatic rings.

\subsection{Mechanism of degradation of dye}

Several studies have reported the increased degradation percentage with the increase in time of exposure of dye and AgNP complex in sunlight $[54,55]$. The reaction did not occur in the absence of AgNPs and even in the presence of nanoparticles in dark [56]. The reaction in the absence of sunlight confirmed the importance of sunlight in the catalytic activity of synthesized nanoparticles. There are two processes, which are involved in the photocatalytic decomposition of dyes, i.e. adsorption and decomposition. The mechanism of degradation of dye could probably be attributed to the surface 
(a)<smiles>O=c1oc2c(O)c(O)cc3c(=O)oc4c(O)c(O)cc1c4c23</smiles>

Ellagic acid

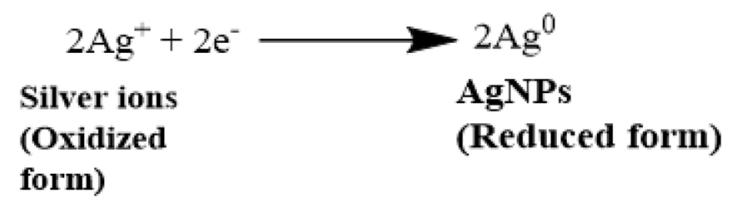<smiles>O=c1oc2c(O[14F])c(O[14F])cc3c(=O)oc4c(O)c(O)cc1c4c23</smiles>

Intermediate complex

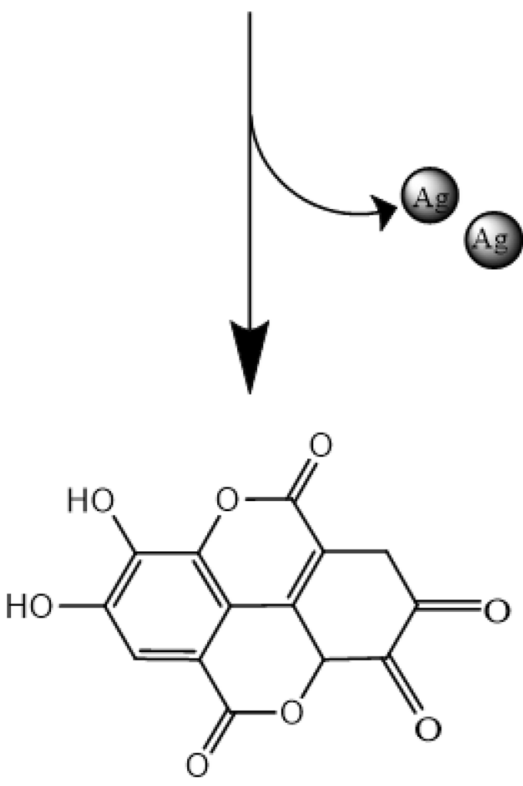

Oxidized form

(keto form)

(b)

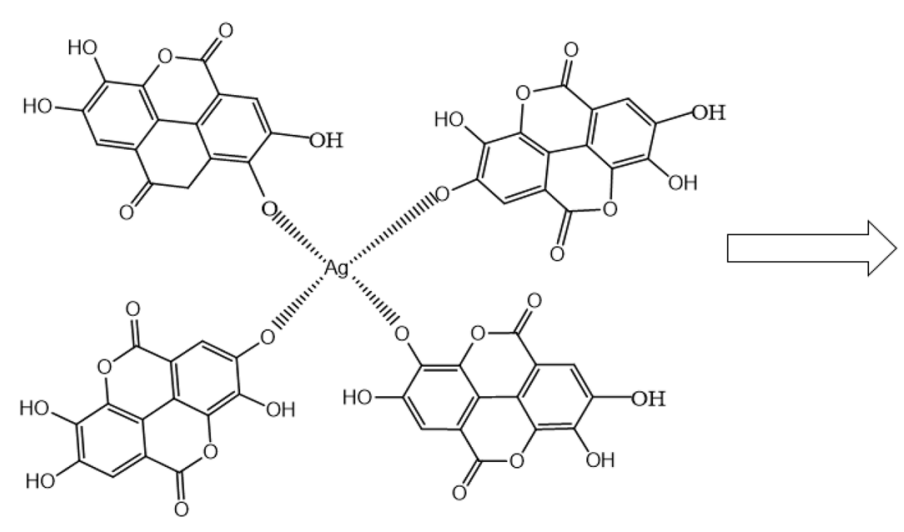

Capping of AgNPs by Ellagic acid

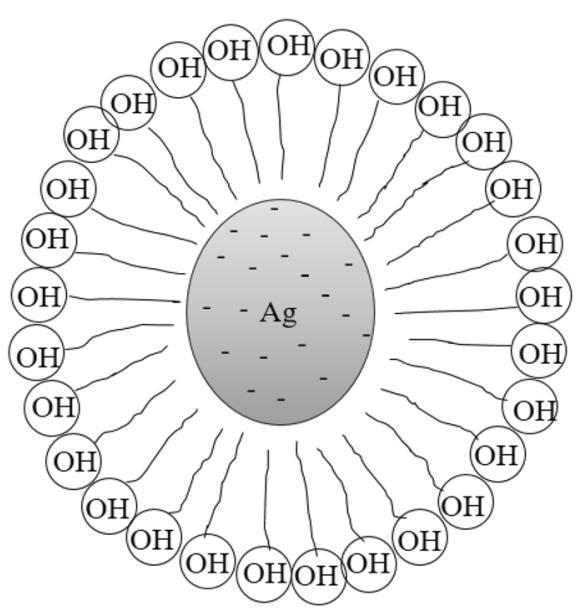

Stabilized AgNPs

Fig. 11 A schematic illustration of the mechanism for formation and stabilization of AgNPs using orange peel. a Redox reaction showing mechanism of mechanism of reduction of $\mathrm{Ag}+$ ions to $\mathrm{AgO}$ by ellagic acid, $\mathbf{b}$ capping and stabilization of AgNPs 

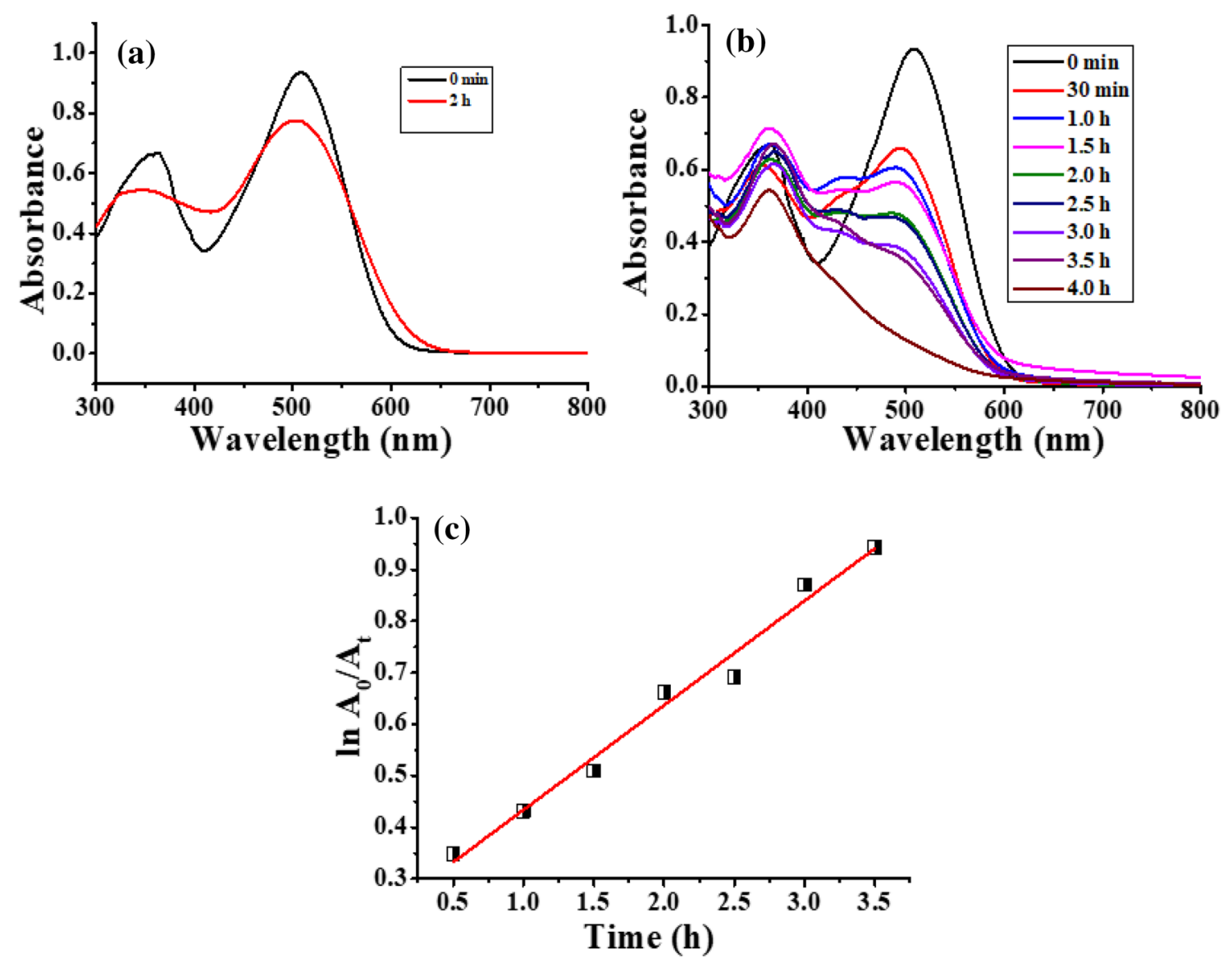

Fig. 12 Time-dependent UV-Vis spectra for the catalytic degradation of Congo red dye using AgNPs $\mathbf{a}$ in the absence of sunlight, $\mathbf{b}$ in the presence of sunlight and $\mathbf{c}$ the plot of $\ln A_{0} / A_{t}$ versus time for the degradation of congo red

plasmon resonance (SPR) effect. The excitation of SPR occurs due to oscillating charge density propagating at the interface between nanoparticles and dielectric medium [57]. The mechanism is similar to the one proposed in the study [58]. $\mathrm{Ag}^{+}$also shows the similar activity as $\mathrm{Cd}$ ions. When nanoparticles are exposed to sunlight, the photons hit the surface and electrons get excited. The oxygen molecule dissolved in the reaction medium accepts the electrons released from the particle surface and gets converted into oxygen anion radicals. These radicals break the organic dye into simple organic molecule, which results in the degradation of dye [59]. Since the process of photocatalysis takes place on the surface of AgNPs, enhancing the surface area available for photocatalysis can have crucial impact on its ability to catalyse the process. The photocatalytic degradation mechanism occurring on the catalyst surface can be explained through the following set of reactions (Eqs. 1-9):

$\mathrm{Ag}+\mathrm{h} v \rightarrow \mathrm{Ag}\left\{\mathrm{e}^{-}(\mathrm{CB})+\mathrm{h}^{+}(\mathrm{VB})\right\}$
$\mathrm{h}^{+}+\mathrm{OH}^{-} \rightarrow \mathrm{OH}$

$\mathrm{h}^{+}+\mathrm{H}_{2} \mathrm{O} \rightarrow \mathrm{OH}$

$\mathrm{O}_{2}+\mathrm{e}^{-} \rightarrow \mathrm{OH}_{2}^{-}$

$\mathrm{O}_{2}^{-}+\mathrm{H}^{-} \rightarrow \mathrm{HO}_{2}$

$\mathrm{HO}_{2} \rightarrow \mathrm{O}_{2}+\mathrm{H}_{2} \mathrm{O}_{2}$

$$
\mathrm{H}_{2} \mathrm{O}_{2}+\mathrm{e}^{-} \rightarrow \mathrm{OH}^{-}+\mathrm{OH}
$$

$$
\mathrm{H}_{2} \mathrm{O}_{2}+\mathrm{O}_{2} \rightarrow \mathrm{OH}^{-}+\mathrm{OH}+\mathrm{O}_{2}
$$

$$
\mathrm{O}_{2}^{-} / \cdot \mathrm{OH}+\text { dye } \rightarrow \text { Degraded Product }
$$




\subsection{Kinetics of degradation of dye}

The kinetics of the sunlight assisted photocatalytic degradation of dye was studied with the help of Langmuir-Hinshelwood model. The linear form of the model is expressed in the form of Eq. 10:

$\ln \left(A_{0} / A_{t}\right)=k t$

where $A_{0}$ is the initial concentration of dye and $A_{t}$ is the concentration of dye at time $t$, slope $(k)$ is the rate constant of the reaction and $t$ is the irradiation time.

The rate of reaction was determined by plotting a graph between $\ln \left(A_{0} / A_{t}\right)$ versus reduction, and slope of the graph depicts the rate of reaction. The order of the reaction was found to be of pseudo-first order, and the rate constant calculated from the slope of the graph was found to be $0.2028 \mathrm{~h}^{-1}$ (Fig. 12c).

\section{Conclusions}

In the study, AgNPs were prepared using green route and stabilized in the presence of orange peel extract. The concentration of peel extract influenced not only the size, PDI and FWHM but also had an effect on colloidal stability of nanoparticles. According to the UV-Vis data obtained, $K_{\mathrm{Ext} / \mathrm{Ag}}=5.0$ is the most optimum concentration for obtaining nanoparticles of higher stability. A considerable increase in the intensity of the UV-Vis spectrum peak was observed in the presence of extract, which indicates synthesis of large number of nanoparticles. FESEM images confirmed the role of peel extract in the synthesis of silver nanoparticles. The morphology and composition of AgNPs are in good agreement with those reported by Gonzalez et al. [60]. The hydrodynamic diameter of the AgNPs was found to be smallest at $\mathrm{pH} 10$ and $45^{\circ} \mathrm{C}$ temperature, and therefore, it was concluded that the optimum condition for the maximum stability of nanoparticles was found to be at $\mathrm{pH} 10$ and $45^{\circ} \mathrm{C}$ temperature. Orange peel is not only cost-effective but is also readily available and hence provides a cheap and easy method to synthesize stable silver nanoparticles, which can be further used for various applications. Synthesized and stabilized AgNPs exhibited good antimicrobial activity against bacteria Pseudomonas syringae and Psedomonas aeruginosa and fungi Alternaria brassicicola. The AgNPs were also capable of degrading Congo red dye efficiently and exhibited higher catalytic activity. Thus, greener route for synthesis of nanoparticles could be used for making comparatively better antimicrobial and catalytic agent for various purposes.
Acknowledgements The authors acknowledge Department of Civil Engineering, IIT-Kanpur, for DLS measurement and Advanced Centre for Materials Science, IIT-Kanpur, for FESEM and XRD analysis.

Funding The authors declare no competing financial interests. This research did not receive any specific grant from funding agencies in the public, commercial or not-for-profit sectors.

\section{Compliance with ethical standards}

Conflict of interest The authors declare that they have no conflict of interest.

\section{References}

1. Ibrahim K, Khalid S, Idrees K (2017) Nanoparticles: properties, applications and toxicities. Arab J Chem 12:908-931. https:// doi.org/10.1016/j.arabjc.2017.05.011

2. Li Z, Wang Y, Yu Q (2010) Significant parameters in the optimization of synthesis of silver nanoparticles by chemical reduction method. J Mater Eng Perform 19:252-256. https://doi. org/10.1007/s11665-009-9486-7

3. Boutinguiza $M$, Comesaña R, Lusquiños F, Riveiro A, Val J, Pou $J$ (2014) Production of silver nanoparticles by laser ablation in open air. Appl Surf Sci 336:108-111. https://doi.org/10.1016/j. apsusc.2014.09.193

4. Kempa TJ, Farrer RA, Giersig M (2006) Photochemical synthesis and multiphoton luminescence of monodisperse silver nanocrystals. Plasmonics 1:45-51. https://doi.org/10.1007/ s11468-006-9008-5

5. Sen P, Ghosh J, Abdullah A, Kumar PV (2003) Preparation of $\mathrm{Cu}, \mathrm{Ag}, \mathrm{Fe}$ and Al nanoparticles by the exploding. J Chem Sci 115:499-508. https://doi.org/10.1007/BF02708241

6. Iravani S (2011) Green synthesis of metal nanoparticles using plants. Green Chem 13:2638-2650. https://doi.org/10.1039/ C1GC15386B

7. Goswami AM, Ghosh S (2013) Biological synthesis of colloidal gold nanoprisms using penicillium citrinum MTCC9999. J Biomater Nanobiotechnol 4:20-27. https://doi.org/10.4236/ jbnb.2013.42A003

8. Pirtarighat S, Ghannadnia M, Baghshahi S (2018) Biosynthesis of silver nanoparticles using Ocimum basilicum cultured under controlled conditions for bactericidal application. Mater Sci Eng C 98:250-255. https://doi.org/10.1016/j.msec.2018.12.090

9. Gopi D, Kanimozhi K, Bhuvaneshwari N, Indira J, Kavitha L (2014) Novel banana peel pectin mediated green route for the synthesis of hydroxyapatite nanoparticles and their spectral characterization. Spectrochim Acta Part A Mol Biomol Spectrosc 118:589-597. https://doi.org/10.1016/j.saa.2013.09.034

10. Roy P (2017) Green synthesis of silver nanoparticles using Azadirachta indica leaf extract and its antimicrobial study. Appl Nanosci 7:843-850. https://doi.org/10.1007/s13204-017-0621-8

11. Veerasamy $R$ et al (2011) Biosynthesis of silver nanoparticles using mangosteen leaf extract and evaluation of their antimicrobial activities. J Saudi Chem Soc 15:113-120. https://doi. org/10.1016/j.jscs.2010.06.004

12. Ahmed S, Ikram S (2015) Silver nanoparticles: one pot green synthesis using Terminalia arjuna extract for biological application. J Nanomed Nanotechnol. https://doi.org/10.4172/21577439.1000309

13. Sajeshkumar NK, Vazhacharickal PJ, Mathew JJ, Sebastin A (2015) Synthesis of silver nano particles from curry leaf 
(Murraya koenigii) extract and its antibacterial activity. J Pharm Sci 4:15-25

14. Ahmad N, Sharma S, Rai R (2012) Rapid green synthesis of silver and gold nanoparticles using peels of Punica granatum. Adv Mater Lett 3:376-380. https://doi.org/10.5185/amlet t.2012.6357

15. Gauthami M, Srinivasan N, Goud NM (2015) Synthesis of silver nanoparticles using Cinnamomum zeylanicum bark extract and its antioxidant activity. Nanosci Nanotechnol Asia 5:2-7. https ://doi.org/10.2174/221068120501150728103209

16. Yeo SY, Lee HJ, Jeong SH (2003) Preparation of nanocomposite fibers for permanent antibacterial effect. J Mater Sci 38:21432147. https://doi.org/10.1023/A:1023767828656

17. Kennedy J et al (2017) Bioreduction potentials of dried root of Zingiber officinale for a simple green synthesis of silver nanoparticles: antibacterial studies. J Photochem Photobiol B 177:62-68. https://doi.org/10.1016/j.jphotobiol.2017.10.007

18. Mocanu A et al (2019) Antimicrobial properties of polysulfone membranes modified with carbon nanofibers and silver nanoparticles. Mater Chem Phys 223:39-45. https://doi.org/10.1016/j. matchemphys.2018.10.002

19. Varadavenkatesan T, Vinayagam R, Selvaraj R (2019) Green synthesis and structural characterization of silver nanoparticles synthesized using the pod extract of Clitoria ternatea and its application towards dye degradation. Mater Today. http://doi. org/10.1016/j.matpr.2019.04.216

20. Rafique $M$ et al (2019) Novel and facile synthesis of silver nanoparticles using Albizia procera leaf extract for dye degradation and antibacterial applications. Mater Sci Eng C 99:1313-1324. https://doi.org/10.1016/j.msec.2019.02.059

21. Bonnia NN et al (2016) Green biosynthesis of silver nanoparticles using 'Polygonum Hydropiper' and study its catalytic degradation of methylene blue. Proc Chem 19:594-602. https://doi. org/10.1016/j.proche.2016.03.058

22. Kant R (2012) Textile dyeing industry an environmental hazard. Nat Sci 4:22-26. https://doi.org/10.4236/ns.2012.41004

23. Hossain L, Sarker SK, Khan MS (2018) Evaluation of present and future wastewater impacts of textile dyeing industries in Bangladesh. Environ Dev 26:23-33. https://doi.org/10.1016/j.envde v.2018.03.005

24. Awual R (2019) Innovative composite material for efficient and highly selective $\mathrm{Pb}(\mathrm{II})$ ion capturing from wastewater. J Mol Liq 284:502-510. https://doi.org/10.1016/j.molliq.2019.03.157

25. Awual R (2019) Novel conjugated hybrid material for efficient lead(II) capturing from contaminated wastewater. Mater Sci Eng, C 101:686-695. https://doi.org/10.1016/j.msec.2019.04.015

26. Awual R et al (2017) Inorganic-organic based novel nanoconjugate material for effective cobalt(II) ions capturing from wastewater. Chem Eng J 324:130-139. https://doi.org/10.1016/j. cej.2017.05.026

27. Awual R, Miyazaki Y, Taguchi T, Shiwaku H, Yaita T (2016) Encapsulation of cesium from contaminated water with highly selective facial organic-inorganic mesoporous hybrid adsorbent. Chem Eng J 291:128-137. https://doi.org/10.1016/j. cej.2016.01.109

28. Kumari $\mathrm{M}$ et al (2016) Tailoring shape and size of biogenic silver nanoparticles to enhance antimicrobial efficacy against MDR bacteria. Microb Pathog 105:346-355. https://doi.org/10.1016/j. micpath.2016.11.012

29. Barani H, Montazer M, Toliyat T, Samadi N (2010) Synthesis of Agliposome nano composites. J Liposome Res 20:323-329. https ://doi.org/10.3109/08982100903544177

30. Barani H, Montazer M, Braun H, Dutschk V (2014) Stability of colloidal silver nanoparticles trapped in lipid bilayer: effect of lecithin concentration and applied temperature. IET Nanobiotechnol 8:282-289. https://doi.org/10.1049/iet-nbt.2013.0048
31. Barani H, Montazer M, Samadi N, Toliyat T (2011) Nano silver entrapped in phospholipids membrane: synthesis, characteristics and antibacterial kinetics. Mol Membr Biol 28:206-215. https://doi.org/10.3109/09687688.2011.565484

32. Chen M, Feng YG, Wang X, Li TC, Zhang JY, Qian DJ (2007) Silver nanoparticles capped by oleylamine: formation, growth, and self-organization. Langmuir 23:5296-5304. https://doi. org/10.1021/la700553d

33. Bar H, Bhui DK, Sahoo GP, Sarkar P, De SP, Misra A (2009) Green synthesis of silver nanoparticles using latex of Jatropha curcas. Colloids Surf A 339:134-139. https://doi.org/10.1016/j. colsurfa.2009.02.008

34. Magudapathy P, Gangopadhyay P, Panigrahi BK, Nair KGM, Dhara S (2001) Electrical transport studies of Ag nanoclusters embedded in glass matrix. Phys B 299:142-146. https://doi. org/10.1016/S0921-4526(00)00580-9

35. Kaviya S, Santhanalakshmi J, Viswanathan B, Muthumary J, Srinivasan K (2011) Biosynthesis of silver nanoparticles using Citrus sinensis peel extract and its antibacterial activity. Spectrochim Acta Part A: Mol Biomol Spectrosc 79:594-598. https ://doi.org/10.1016/j.saa.2011.03.040

36. Keshavamurthy M, Srinath BS, Rai VR (2017) Phytochemicals mediated green synthesis of gold nanoparticles using Pterocarpus Santalinus L. (Red Sanders) bark extract and their antimicrobial properties. Part Sci Technol 36:785-790. https://doi. org/10.1080/02726351.2017.1302533

37. Rajeshkumar S (2016) Synthesis of silver nanoparticles using fresh bark of Pongamia pinnata and characterization of its antibacterial activity against gram positive and gram negative pathogens. Resour Eff Technol 2:30-35. https://doi. org/10.1016/j.reffit.2016.06.003

38. Carlson C, Hussain SM, Schrand AM, Hess KL, Jones RL, Schlager JJ (2008) Unique cellular interaction of silver nanoparticles: size-dependent generation of reactive oxygen species. J Phys Chem 112:13608-13619. https://doi.org/10.1021/ jp712087m

39. Dibrov $\mathrm{P}$ et al (2002) Chemiosmotic mechanism of antimicrobial activity of $\mathrm{Ag}+$ in Vibrio cholerae. Antimicrob Agents Chemother 46:8-11. https://doi.org/10.1128/ AAC.46.8.2668-2670.2002

40. Sondi I, Salopek-sondi B (2004) Silver nanoparticles as antimicrobial agent: a case study on E. coli as a model for Gram-negative bacteria. J Colloid Interphase Sci 275:177-182. https://doi. org/10.1016/j.jcis.2004.02.012

41. Feng QL, Wu J, Chen GQ, Cui FZ, Kim TN, Kim JO (2000) A mechanistic study of the antibacterial effect of silver ions on Escherichia coli and Staphylococcus aureus. J Biomed Mater Res 52:662-668. https://doi.org/10.1002/1097-4636(20001 215)52:4\%3C662:aid-jbm10\%3E3.0.co;2-3

42. Ren $Y$, Yang H, Wang T, Wang C (2019) Bio-synthesis of silver nanoparticles with antibacterial activity. Mater Chem Phys 235:121746. https://doi.org/10.1016/j.matchemphy s.2019.121746

43. Fu PP, Xia Q, Hwang HM, Ray PC, Yu H (2014) Mechanisms of nanotoxicity: generation of reactive oxygen species. J Food Drug Anal 22:64-75. https://doi.org/10.1016/j.jfda.2014.01.005

44. Makarov VV, Love AJ, Sinitsyna OV, Makarova SS, Yaminsky IV (2014) Green' nanotechnologies: synthesis of metal nanoparticles using plants. Acta Nat 6:35-44

45. Daneshfar A, Ghaziaskar HS, Homayoun N (2008) Solubility of gallic acid in methanol, ethanol, water, and ethyl acetate. J Chem Eng 53:776-778. https://doi.org/10.1021/je700633w

46. Dhawan D, Gupta J (2016) Comparison of different solvents for phytochemical extraction potential from datura metel plant leaves. Int J Biol Chem 11:17-22. https://doi.org/10.3923/ ijbc.2017.17.22 
47. Silvert PY, Herrera-Urbina R, Tekaia-Elhsissen K (1997) Preparation of colloidal silver dispersions by the polyol process. J Mater Chem 7:293-299

48. Hider RC, Liu ZD, Khodr HH (2001) Metal chelation of polyphenols. Methods Enzymol 335:190-203. https://doi.org/10.1016/ s0076-6879(01)35243-6

49. Ky I, Lorrain B, Kolbas N, Crozier A, Teissedre PL (2014) Wine by-Products: phenolic characterization and antioxidant activity evaluation of grapes and grape pomaces from six different French grape varieties. Molecules 19:482-506. https://doi. org/10.3390/molecules 19010482

50. Jacob JA et al (2008) Role of phenol derivatives in the formation of silver nanoparticles. Langmuir 24:528-533. https://doi. org/10.1021/la702073r

51. Maiti S, Purakayastha S, Ghosh B (2008) Production of low-cost carbon adsorbents from agricultural wastes and their impact on dye adsorption. Chem Eng Commun 195:386-403. https://doi. org/10.1080/00986440701707917

52. Yokoyama K, Fisher AD, Amori AR, Welchons DR, Mcknight RE (2010) Spectroscopic and calorimetric studies of congo red dyeamyloid B peptide complexes. J Biophys Chem 1:153-163. https ://doi.org/10.4236/jbpc.2010.13018

53. Movahedi M, Mahjoub AR (2009) Photodegradation of Congo red in aqueous solution on $\mathrm{ZnO}$ as an alternative catalyst to $\mathrm{TiO}_{2}$. Iran Chem Soc 6:70-577. https://doi.org/10.1007/BF03246536

54. Roshmi T, Jishma P, Radhakrishnan EK (2016) Photocatalytic and antibacterial effects of silver nanoparticles fabricated by Bacillus subtilis SJ 15. Inorg Nanometal Chem 3174:901-908. https://doi. org/10.1080/15533174.2016.1228668
55. Vanaja M et al (2014) Degradation of methylene blue using biologically synthesized silver nanoparticles. Bioinorg Chem Appl 2014:1-8. https://doi.org/10.1155/2014/742346

56. Roy K, Sarkar CK, Ghosh CK (2014) Photocatalytic activity of biogenic silver nanoparticles synthesized using yeast (Saccharomyces cerevisiae) extract. Appl Nanosci 5:953-959. https://doi. org/10.1007/s13204-014-0392-4

57. Garcia MA (2011) Surface plasmons in metallic nanoparticles: fundamentals. J Phys D Appl Phys 44:283001. https://doi. org/10.1088/0022-3727/44/28/283001

58. Nasir JA et al (2018) Efficient solar light driven photocatalytic degradation of Congo red dye on CdS nanostructures derived from single source precursor. J Nanosci Nanotechnol 18:74057413. https://doi.org/10.1166/jnn.2018.16038

59. Edison TNJI, Atchudan R, Sethuraman MG, Lee YR (2016) Reductive-degradation of carcinogenic azo dyes using Anacardium occidentale testa derived silver nanoparticles. J Photochem Photobiol B 162:604-610. https://doi.org/10.1016/j.jphotobiol .2016.07.040

60. Gonzalez AL, Noguez C, Beranek J, Barnard AS (2014) Size, shape, stability, and color of plasmonic silver nanoparticles. J Phys Chem 118:9128-9136. https://doi.org/10.1021/jp5018168

Publisher's Note Springer Nature remains neutral with regard to jurisdictional claims in published maps and institutional affiliations. 